\title{
Explaining Emigration Intentions and Behaviour in the
}

Netherlands, 2005-10

\author{
Hendrik P. van Dalen ${ }^{\mathrm{a}, \mathrm{b}}$ and Kène Henkens ${ }^{\mathrm{a}, \mathrm{c}}$ \\ 8 May 2012
}

(a) Netherlands Interdisciplinary Demographic Institute (NIDI)

P.O. Box 11650

NL-2502 AR The Hague

The Netherlands

Email: dalen@ nidi.nl

Tel: +3170-35653237

Fax: +31703647187

(b) Tilburg University

Tilburg School of Economics and Management (TISEM), and CentER

P.O. Box 90153

NL-5000 LE Tilburg

The Netherlands

(c) Tilburg University

Department of Sociology

P.O. Box 90153

NL-5000 LE Tilburg

The Netherlands

This is a post-print version of the paper which appeared in Population Studies. Please consult the printed version in Population Studies for quotes and cite this paper as: H.P. van Dalen, and K. Henkens, 2013, Explaining Emigration Intentions and Behaviour in the Netherlands, 2005-10, Population Studies, Volume 67(2), 225-241.

DOI: $10.1080 / 00324728.2012 .725135$

Running head: Explaining Emigration Decisions

JEL codes: J61, F22, D84

Keywords: emigration, intentions, behaviour, personality, brain drain 


\begin{abstract}
The present study examines the emigration intentions of native-born Dutch residents and their subsequent emigration behaviour from 2005-10. Data were collected from two surveys on emigration intentions, one conducted locally and one nationally. A number of novel results stand out. First, intentions were good predictors of future emigration; 34 per cent of those who had stated an intention to emigrate actually emigrated within the fiveyear follow-up period. Second, the personality of potential migrants and their discontent about the quality of the public domain in the Netherlands (e.g. mentality, crowded space and nature, pollution, crime) were the strongest driving forces for moving abroad. Third, the main difference between movers and those who stated intentions to emigrate but had not (yet) followed through was their state of health: healthy people were more likely to follow through with their migration intentions than those in poorer health.
\end{abstract}




\section{Introduction}

'A great emigration necessarily implies unhappiness of some kind or other in the country that is deserted. For few persons will leave their families, connections, friends, and native land, to seek a settlement in untried foreign climes, without some strong subsisting causes of uneasiness where they are, or the hope of some great advantages in the place to which they are going.'

Thomas Malthus in Essay on the Principle of Population (1798, chapter II)

These lines by Thomas Malthus capture succinctly the psychological stress that accompanies migration, the discontent with the country of origin, and the dreams and expectations about the destination country. It is relatively easy to understand why people leave their home countries in poverty-stricken regions of the world. However, the emigration of native-born citizens of high-income countries is more puzzling.

At the start of the twenty-first century, a number of Western European countries witnessed a remarkable upswing in emigration (see Salt and Rees 2006; Vandenbrande et al. 2006; Van Dalen and Henkens 2007). For instance, in the United Kingdom, Germany, and the Netherlands, the rise in emigration has been steady and substantial. In the Netherlands, the level of emigration in 2006 even surpassed that of the emigration wave of the 1950s, a time when Dutch people lost confidence in the future of the country, and housing shortages and unemployment were at the forefront of public debate (Petersen 1952). 
In the current era of globalisation, understanding the decisions behind international migration is of increasing importance. However, only limited insights have been gained thus far into the determinants that underlie the emigration decisions of individuals in highly developed countries and the degree to which migrants' intentions are followed by actual behaviour. The present paper fills the gap in the body of knowledge on this topic by addressing the following three research questions:

(1) What are the main predictors of the emigration intentions of native-born Dutch residents?

(2) To what degree are these intentions good predictors of subsequent behaviour?

(3) Do groups of respondents differ with respect to the degree to which they realise their emigration intentions?

By studying intentions and behaviour, this paper combines the insights that have been provided by two strands of literature on decision-making in relation to international migration, namely the strand that relies on revealed preferences and the one that relies on stated preferences. The revealed preferences approach has often been used by economists (Borjas 1987, 1991; Hatton and Williamson 1998, 2011) to focus on the actual movements of people; the basic premise being that people's preferences are revealed by their actual behaviour. In contrast, social demographers, geographers, and psychologists tend to use the stated preferences approach to understand intentions to emigrate (De Jong 2000; Van Dalen et al. 2005; Drinkwater and Ingram 2009). However, a focus on intentions and subsequent behaviour might enable us to understand better the complexity of decision-making processes with respect to international migration. 
Although the analysis of migration intentions generates insights about the differences between potential emigrants and those who want to remain, and the reasons why the former want to leave, scholars have tended to avoid using this approach (cf. Sutton 2003). For instance, Constant and Massey (2002, p. 23) state that 'intentions are notoriously unreliable as guides to eventual behaviour'. The step from intentions to actual behaviour may be affected by intervening circumstances which make intentions imperfect measures of subsequent behaviour.

However, studies that examine only actual migration behaviour might also provide an incomplete view of the migration forces at work, because they focus on situations in which selection has already occurred. Liebig and Sousa-Poza (2004, p. 126) point out that one of the most significant drawbacks of this approach is that actual migration decisions may be influenced strongly by the restrictions that are imposed by potential destination countries.

Unfortunately, scarce research on international migration has linked behavioural intentions with subsequent actual migration behaviour. Migration research that combines intentions with behaviour is restricted primarily to internal migration (Duncan and Newman 1976; Hughes and McCormick 1985; Lu 1998, 1999; Kan 1999), and the only study that examines this link in relation to cross-border migration is an early study of rural areas in the Philippines by Gardner et al. (1986).

The present study focuses on the case of a high-income country, namely the Netherlands. The emigration upsurge of the past decade in the Netherlands has remained somewhat of an enigma to scholars and policymakers. Why leave a country where the 
income level is high, public services are extensive, and the standard of living is the envy of immigrants from less developed countries?

In this paper, we argue that to elucidate the driving forces behind emigration from high-income countries, researchers must look beyond the traditional economic model of migration in which (net) private gains dominate the decision-making process. Thus, in addition to the traditional driving forces that are considered to influence migration, namely economic considerations, we include non-monetary forces that are exerted by social networks and personality traits in our analyses of emigration decisions. The inclusion of these elements in a study of this kind has been emphasised previously by both psychologists (Berry 2001; Frieze and Li 2010) and sociologists (De Jong and Fawcett 1981; De Jong 2000).

In addition, we examine how dissatisfaction with various aspects of the public domain affects migration decisions in a high-income country. These aspects involve both public institutions (social security, the educational system, and law and order) and the 'public goods' that these institutions produce, such as social protection, safety, environmental quality, and education. A number of previous studies (cf. Borjas and Bratsberg 1996; Hugo et al. 2001; DeVoretz and Iturralde 2001; Uebelmesser 2006; Poutvaara et al. 2009; Geis et al. 2011) have focused on explaining emigration from highly developed countries, but none has paid attention to both the public and the private domains of life.

\section{A migration decision-making framework}


Most theories on migration are based on the assumption that people behave in ways that yield improvements in welfare. In economic theory, the benefits of migration are defined in general in terms of positive net wage difference (i.e. wage differences corrected for the material and immaterial costs of moving). Sociologists emphasise the importance of social networks in improving welfare (Boyd 1989), whereas psychologists examine whether personality characteristics affect migration decisions (see Berry 2001). Social psychologists address the behavioural intentions that precede actual migration. According to the theory of reasoned action (Fishbein and Ajzen 1975; Ajzen and Fishbein 1980; Sutton 1998), behavioural intention is both the immediate determinant and the single best predictor of behaviour. The theory specifies the two determinants of intention that are necessary to perform a given behaviour: (1) the attitude towards the behaviour in question, which is the person's overall evaluation of performing the behaviour, and (2) subjective norms, which is the person's perceived expectations of significant others with regard to his or her performing the behaviour in question. In addition to these two driving forces, the theory of planned behaviour (Ajzen 1991) adds a third determinant to cover behaviours that are not completely under volitional control. This determinant is often referred to as perceived behavioural control, namely the degree to which a person feels he or she has control over performing the behaviour or the perceived ease of performing the behaviour (i.e. their 'self-efficacy').

The theory of reasoned action is typically set up as a causal model in which norms, attitudes, and behavioural control form the intention, which in turn is the sole predictor of behaviour (for an overview of the various methodological intricacies of testing attitude/behaviour theories, see Sutton 2003). In our study of the emigration 
intentions and behaviour of native-born Dutch residents, we incorporate the determinants of the different disciplinary approaches into one analytical framework. We thereby combine the structural variables that are usually included in economic and sociological studies with the attitudinal characteristics that are often included in the work of social psychologists.

Our study extends earlier research on emigration along two lines. First, we pay attention to those individual characteristics that are considered to underlie the economic, social, and psychological expected net benefits of emigration. Second, to understand emigration from a high-income country, we focus on factors that refer to individual characteristics and the private domain of life as well as on the perceived quality of the public domain in the source country. Below, we expand on each of these factors, beginning with the most common driving force, namely human capital.

\section{Human capital}

Economic influences on migration are the starting point of the present analysis. In its most basic form, the decision to emigrate is simple: as long as the benefits of migration exceed the costs (such as foregone earnings and direct moving costs), migration is a profitable option. Given that migration is often viewed as a way of capturing the globally diverse rents or net benefits of human capital (Sjaastad 1962), human capital theory is crucial to understanding international migration, or in more general terms, the mobility of labour.

In general, human capital can be defined as the personal accumulation of investments in the ability to be productive, whereby education, training, and health are 
the most important of such investments (Becker 1975). Regarding the most obvious element - education - a large number of economic migration studies have questioned whether migration flows occur disproportionately among the skilled workforce of a source country.

The theory of labour migration suggests that the tendency to emigrate is higher among the highly skilled workers of a source country than among the unskilled population. Whether so-called positive self-selection takes place is not self-evident a priori, because it depends on the wage structure, both at home and abroad, as well as the direct and indirect costs of migration, such as foregone earnings and the out-of-pocket expenditure that is tied to migration. However, it is clear that those who earn a high wage are motivated to move from a country with a compressed income distribution to one that has a more unequal distribution. Given that the country with the compressed income distribution 'taxes' high-wage earners and 'insures' low-wage earners, by moving highwage earners can escape high taxes and benefit from the relatively low taxes in the destination country. Granted the fact that the inequality of income in the Netherlands is relatively low, positive selectivity would be expected in relation to moving to AngloSaxon countries such as the US, the UK, and Australia, where income inequality is relatively high (OECD 2011, pp. 66-67). Chiswick (1999) further claims that positive selectivity also occurs because higher-skilled individuals can recoup the out-of-pocket costs of migration faster and because they adapt more easily to the prevailing conditions of the destination country (e.g. its language, norms, and rules) than lower-skilled workers. Thus, with regard to emigration from high-income countries, we expect that the 
higher educated part of the population will be more inclined to migrate because their human capital is more transferable internationally

The influence of health status on people's emigration decisions follows the logic of the human capital model closely, because potential migrants can recoup the investment costs of migration only if their health is good. In other words, poor health is associated with a lower likelihood of emigration.

Moreover, migration decisions are in general age-related, with the likelihood of migration decreasing as people grow older. The reason why age has such a large influence in empirical studies of migration is twofold. First, the accumulation of human capital is related strongly to life cycle. At the start of the life cycle, careers are not yet developed fully and plans are flexible, which implies greater mobility. Second, age may capture cohort effects. The current younger generation are more highly educated than are older cohorts and the 'Americanisation' of educational systems has resulted in English becoming the lingua franca across most of Europe, which thus makes human capital more transferable across borders (Borghans and Cörvers 2010).

\section{Social forces}

The making of migration decisions is not purely an individual pursuit; the influence of social networks and pressure from family, friends, and co-workers are bound to affect people’s decisions to emigrate (Mincer 1978; Stark and Bloom 1985). In other words, social forces in the home and destination countries might influence the actual decisionmaking process in relation to migration. 
A more extensive network of relational ties in the home country increases social and psychological well-being (Thoits 2011) and can be assumed to reduce the likelihood of emigration. Strong ties to children and spouses are assumed to be a major restricting factor in the decision to migrate; indeed, the empirical literature on this topic affirms in general that flows of migration are dominated by people who do not have a partner (see Krieger 2005).

Whereas the social network in the home country might restrict migration, the availability of a social network abroad is believed in general to increase its probability. The role that is played by migrant networks has been well established in the work of previous authors (Massey 1999; Epstein and Gang 2006). Friends and family who live abroad (although not necessarily in the preferred destination country) offer access to a broad range of experiences, and they may introduce the option of emigration and subsequently offer help or information in effecting the move abroad. Consequently, most previous studies have assumed a relation between the (adjustment) costs of migration and the size of the available social network in the destination country. The present study tests the hypothesis that the larger the number of emigrants in an individual's network, the higher the likelihood of emigration is.

\section{Personality traits}

Leaving one's home country can give rise to strong feelings of uncertainty, because living and working abroad implies the need to become acquainted with a new culture or even adapt one's identity. Consequently, psychological characteristics are assumed to predict whether people will choose to enter a new and unfamiliar situation, as well as 
their affective reactions to doing so. Borghans et al. (2008) recently made a persuasive case of how personality traits affect socioeconomic outcomes in a broad range of domains (although migration was not one of them), and how the use of these traits can increase the predictive power of standard economic models.

In the present paper, we focus on two personality traits that might influence emigration intentions, namely sensation-seeking and self-efficacy. Sensation-seeking (Horvath and Zuckerman 1993) might influence the decision-making process in relation to international migration greatly because sensation-seekers take more risks and perceive the world to be less threatening. Thus, the more adventurous or risk-loving a person is, the stronger his or her intention to emigrate will be and the more likely actual emigration becomes. The second trait, self-efficacy, is defined as the belief that an individual can cope with a given situation and thus it can be used as a predictor of whether he or she will choose to enter a new and unfamiliar situation (Sherer et al. 1982). Self-efficacy predicts confidence in the ability to deal with changes and unfamiliar situations such as emigration. Uncertainty about how migration will turn out is high because international migration represents a move that devalues country-specific skills and knowledge as well as experience of the labour market. Once in the destination country, migrants must become accustomed to a new culture and acquire a new social network. In light of the foregoing, we assume that higher scores on self-efficacy are associated with stronger intentions to emigrate and an increased likelihood of subsequent emigration.

\section{Quality of the public domain}


The basic theory of migration assumes tacitly that migrants are driven by the differences in utility that are derived from private consumption financed by private lifetime wealth. However, it makes sense to assume that international migration is not only driven by private goods but also public goods or public amenities (Knapp and Graves 1989). In the present study, we argue that the public domain may affect relative prices, but that it is valued primarily for its own sake. In our view, the perceived quality of the public domain depends on how citizens perceive the way in which government institutions function and the public goods and services that are produced by these institutions.

Public goods are defined traditionally as goods that are non-excludable (i.e. no individual can be excluded from using the public good in question) and non-rivalrous (i.e. access by one user to the good does not diminish other people's capacity to benefit from it). However, public goods should be interpreted broadly because such 'goods' are, by definition, a response to a situation in which externalities are complex. In other words, most citizens benefit from the provision of a good, but every individual is tempted to free ride on the efforts of others.

For instance, silence is valued by most citizens, but to 'produce' silence everyone must act in accordance with the rules, certainly in densely populated areas or wherever air, road, or rail traffic is heavy. In some cases, where externalities are straightforward, private transactions or negotiations can solve the problem, but once the transaction costs that are tied to individual corrective action become excessively high, collective action might be necessary. Thus, perceptions of the quality of the public domain are a reflection of both the 'goods' and the governance institutions that try to correct the externalities of individual action (Kaul and Mendoza 2004). 


\section{Methods and data}

Migration data were collected using a two-step approach. First, an emigration survey was conducted from October 2004 to January 2005 using a targeted sampling method

(Watters and Biernacki 1989). The aim of this survey was to oversample potential emigrants to alleviate the problem that the number of potential emigrants in (relatively small) nationally representative samples was expected to be too low to produce reliable analyses.

Visitors to an Expat fair who saw themselves as potential emigrants were asked to participate in the survey. The Expat fair was a meeting ground for 'those who want to work, live, study, do business, and settle abroad'. Visitors were asked to indicate whether they considered themselves to be (1) expatriates, (2) potential emigrants, (3) interested in studying abroad, (4) officers of human resource management or multinationals, or (5) those interested in doing business abroad. We focused exclusively on the second category as representative of those who were contemplating leaving the Netherlands on a permanent basis. A total of 533 potential emigrants received a questionnaire and 214 questionnaires were returned (response rate: 40 per cent).

The second step consisted of a nationwide emigration survey, which was carried out in January $2005(\mathrm{~N}=1,275)$. The survey was conducted by CentERdata, a survey institute of Tilburg University (for details, see http://www.centerdata.nl/en/) that maintains a nationally representative panel of households in the Netherlands. The survey questions were identical to those administered to the participants of the Expat fair. 
To measure emigration behaviour, we tracked all respondents - that is, those with and those without emigration intentions in 2005 - to assess whether they emigrated during the subsequent five years, using the population database of Statistics Netherlands. This database contains information provided by the municipal population registration, which is the official basis for registering migration flows in the Netherlands. Given the full coverage of the Dutch population, there was no attrition during those five years. Although we collected information on return migration, we did not analyse the data because the numbers were too small to enable sound statistical analysis. Given that return migrants had emigrated after we evaluated their migration intentions in 2005 , we treated them as emigrants in the present analysis.

In order to test for biases in the sampling method, we compared the 148 people in the sample from the Expat fair who stated an intention to emigrate with the 38 people in the nationally representative sample who also stated an intention to emigrate. We found no statistically significant differences in relation to the socio-demographic variables of age, education, income, and sex (see Table A1 in the appendix to this paper). Table $1 \mathrm{~A}$ also compares the actual emigrants in the two samples, numbering 65 and 12 , respectively. They differed only in terms of sex and age. Given the small number of emigrants in the nationally representative sample, some divergence is to be expected. These two samples were combined to analyse emigration intentions and subsequent emigration behaviour in the Netherlands $(\mathrm{N}=1,489)$.

Our approach of oversampling potential emigrants enabled us to study the determinants of emigration with a normal-sized survey. Although this approach is new in emigration research, it has been adopted previously in other areas of inquiry, such as 
research into divorce (Kalmijn et al. 2004). Further, given that our sampling strategy increased the proportion of emigrants in the dataset, multivariate analyses were carried out using sample weights that were a function of the dependent variable, namely intention to emigrate (Winship and Radbill 1994).

\section{Dependent variable}

Emigration intention was measured by an ordered categorical variable that represented the response to the question: Are you planning to emigrate in the near future? ('Bent $u$ in de toekomst van plan te emigreren?'). The question as formulated in Dutch combines two elements: it stresses the element of planning, while the verb 'to emigrate' in Dutch connotes that respondents are considering a permanent and distant move. The answer categories were (1) no, certainly not; (2) no, probably not; (3) maybe; (4) yes, probably; and (5) yes, certainly. The emigration intention was treated as an ordinal variable.

\section{Independent variables}

Human capital. This was represented by education and health. Education was defined by the highest attained level of education: the reference category was a low level of education (lower vocational training or primary school). The other dummy variables were intermediate level of education (high school, intermediate vocational training), and high level of education (university and higher vocational training). Health status was derived from responses to the question 'How do you rate your health status in general?: (1) very bad, (2) reasonably bad, (3) not good/not bad, (4) reasonably good, (5) very good. Health was treated as an ordinal variable. 
Social forces. These were measured by household composition and social networks abroad. Two variables described household composition:, a dummy variable partner distinguished those with a partner from those without (the reference category was those without partner); and number of children, provided as the response to the question 'How many children are there currently in your household?'. Further, we used the variable network contacts abroad, which was defined by the response to the question 'Do you know family members and friends who have emigrated?, and if so, how many?'. The quantitative value of this variable was formed from the number of contacts that the respondents had.

Personality traits. Personality was captured by two scale variables, namely 'self-efficacy' and 'sensation-seeking'. Self-efficacy was measured by the following items, which were assessed using a five-point Likert-type scale (cf. Bosscher and Smit 1998): (i) 'When I make plans, I am convinced that I will succeed in carrying them out'; (ii) 'When I decide to do something, I firmly cling to that decision'; and (iii) 'When unexpected problems occur, I do not handle them well'. The response categories varied from 'totally agree' (1) to 'totally disagree' (5). The coding of items (i) and (ii) was reversed to calculate the scale, which indicated the average score for the items. Hence, the higher the score on the scale, the higher was the level of self-efficacy. The internal consistency of the scale was tested by calculating Cronbach's alpha (see Nunnally 1978), which was 0.61 and thus the scale is deemed to be valid. 
The scale variable sensation-seeking was derived from the responses to a set of questions that were assessed with a five-point Likert-type scale (cf. Zuckerman 1971). The following items were included: (i) 'New and unexpected experiences give me the excitement I need in life'; (ii) 'When I have to work according to fixed rules, I easily get fed up with them'; and (iii) 'People or things that always stay the same bore me'.

Respondents answered on a five-item scale that ranged from (1) 'totally agree' to (5) 'totally disagree'. This scale indicates the average score of the items (Cronbach's alpha = 0.64). Again, the higher the score on this scale, the higher was the level of sensationseeking .

Evaluation of home country. To construct the scales for respondents' evaluations of their home country, analyses were carried out in two steps. The first step consisted of establishing whether opinions on the public domain could be traced back to one or more underlying dimensions. Therefore, we carried out an exploratory factor analysis using the answers to the 16 different items in the questionnaire that concerned dissatisfaction with the public and private domains of their home countries. Respondents were asked the following question: 'How do you rate the following aspects in your home country?' All items were evaluated using the following five responses and corresponding values: (1) very positive, (2) positive, (3) neutral, (4) negative, and (5) very negative. As shown in Table A2 (in the appendix of this paper), the 16 items can be grouped into the following four dimensions.

Private living conditions: a dimension based on the respondents' evaluations of their homes, incomes, working conditions, and social contacts. 
Welfare state institutions: a dimension based on the respondents' evaluations of the health care system, social security system, educational system, system of law and order, and pension system.

Environmental quality: a dimension based on the respondents' evaluations of the amount of nature and space, population density, and level of noise pollution.

Societal problems: a dimension based on the respondents' evaluations of the crime level, level of pollution, mentality of the people, and level of ethnic diversity.

In the second step, four scales were constructed on the basis of the average scores of the items with a factor loading of 0.50 or more. The computed Cronbach's alphas were 0.68 for private living conditions, 0.85 for welfare state institutions, 0.75 for environmental quality, and 0.67 for societal problems.

Controls. We also included a number of individual background characteristics as control variables: age, defined in years; sex, with male as the reference category; and income of the household, defined as net income per month. To allow for nonlinear effects in income, we constructed three dummy variables: the reference category of 2500 euros or less, the category of 2500-4000 euros, and the category of more than 4000 euros. We also used employment status, which was self-reported and comprised of three dummy variables: the base category of employees; those not working (retired, disabled, unemployed, homemakers, or students); and those who were self-employed.

The descriptive statistics for all explanatory variables are presented in Table 1, disaggregated by those who emigrated and those who did not. 
HERE TABLE 1: Descriptive statistics of emigrants versus stayers

\section{Do emigration intentions predict behaviour?}

According to our nationally representative sample, in 2005 three per cent of the Dutch population had plans to emigrate in the near future. Table 2 shows that after five years, 46 per cent of those respondents who rated their emigration plans for the near future as highly probable ('yes, certainly') had actually emigrated. Of those who responded 'probably', 16 per cent had emigrated. Taking both categories together, the rate of migration for those who had expressed an intention to emigrate was 34 per cent. Subsequent emigration among respondents who claimed to have no emigration plans at all was extremely rare.

HERE TABLE 2: From emigration intentions to behaviour, 2005-10

Although the statistics in Table 2 suggest how well intentions predict future behaviour, the theory of reasoned action claims that behavioural intentions are the best predictors of behaviour. Consequently, we carried out multivariate regression analyses to test the model of reasoned action more formally. First we present a model that explains emigration intentions (model I) and then a model (model II) that predicts emigration behaviour by intentions in addition to the predictors of model I. Table 3 presents the outcomes. 
HERE TABLE 3: Do intentions predict emigration behaviour? An analysis of emigration intentions and behaviour

As also demonstrated by the work of previous authors, model I shows that the intention to emigrate in 2005 was correlated positively with the respondents' level of education and income and that it was concentrated among men, the young, and those who had an extensive network abroad. However, the novel explanatory predictors were also found to be valuable in relation to understanding intentions, because the more dissatisfied respondents were with their private living conditions and the quality of the public domain (welfare state institutions and environmental conditions), the higher was the probability that they planned to leave. Furthermore, personality was also important in understanding intention to emigrate: being in control and a sense of adventure increased the probability of expressing an intention to leave.

In model II, these predictors were included in addition to intentions in relation to emigration, and the model demonstrates that the probability of actually emigrating increased with the level of certainty with which respondents stated their intentions. On the basis of the goodness-of-fit measure of this logit analysis (Pseudo $\mathrm{R}^{2}=0.39$ ), the model was reasonably good. More importantly, the regression outcomes suggested that the central hypothesis of the theory of reasoned action cannot be rejected. In other words, intentions are the best predictors of behaviour. Only the age of the respondent added significantly to the explanatory power of the model, which suggested that age is related to the discrepancy between intentions and behaviour. 


\section{Anatomy of intentions and behaviour}

Although the previous analysis showed that intentions are good predictors of future behaviour, they are certainly not perfect. Thus, the next step in dealing with intentions and behaviour was to disaggregate the analysis to understand the differences between groups of movers and stayers. By matching intentions with behaviour, four groups (labelled groups I to IV) could be distinguished. Table 4 summarises this information by providing figures for each group from the emigration survey.

HERE TABLE 4: Groups for the analysis of intentions and behaviour

Two groups (I and IV) followed through with their plans, namely the 'movers', who had emigration plans and who actually moved within five years, and the 'stayers', people who had no emigration plans at all and who did not migrate. The groups that did not follow through with their plans within five years (groups III and II) are also interesting, however. Group III constituted, for lack of a better term, 'dreamers', people who had intentions to migrate but who had not realised those plans within five years. Finally, group II was the smallest, and comprised people who initially had no emigration plans but actually emigrated within the five year period (described as 'unintended migrants').

The four groups were analysed jointly by means of multinomial logit analyses, with stayers as the reference category. The results of these multinomial logit analyses are presented in Table 5. 
HERE TABLE 5: Multinomial logit analysis explaining emigration behaviour, weighted results $(\mathrm{N}=1,489)$

Column 1 in Table 5 shows clearly how important age, sex, and health status were in relation to international migration. We found that emigration was much more likely among the young, those who consider themselves to be healthy, and men. Interestingly, however, although Table 1 shows that emigrants were relatively highly educated compared with those who had not yet emigrated, the results of the multivariate model in Table 5 show that education did not exert an independent selective force on the emigration process. This might be because the model presented here is far richer in its choice of determinants than most empirical economic models in previous studies, which rely predominantly on a number of socio-economic characteristics. Our model covered not only socio-economic characteristics but also psychological characteristics, and this might partly explain our finding regarding level of education.

Indeed, the results of the estimation in the first column revealed a number of new findings about emigration in comparison with previous studies. The most influential factors behind emigration behaviour were personality traits and a negative evaluation of the Dutch public domain. In terms of psychological disposition towards migration, the results implied that the ability to make plans work (self-efficacy) and the willingness to seek new adventures and take risks (sensation-seeking) influenced migration decisions. However, dissatisfaction with environmental quality (in terms of space for nature) and societal problems in the Netherlands were also of key importance to understanding recent migration outflows. The finding that perceived inadequacies in the Dutch public domain, 
more than dissatisfaction with private living conditions, were at the forefront of the reasons behind decisions to emigrate was novel.

Column 2 in Table 5 presents the results for dreamers, those who stated an intention to emigrate but who had not done so (yet). The picture that emerged here was highly similar to the above-described results for movers, namely that dreamers were also highly dissatisfied with the quality of the public domain. The importance of perceptions of the quality of public living conditions in the Netherlands is clarified further in Figure 1 , in which we present the underlying individual items divided into the three most important groups: movers, stayers, and dreamers.

HERE FIGURE 1: Evaluation of living conditions in the Netherlands, by migration status

It is clear from our findings that movers and dreamers were more negative about all dimensions of private and public living conditions than those who had no plans to emigrate. Population density was in particular a major push factor for Dutch people, whereas living conditions in the Netherlands (such as work, income, and social contacts) were largely viewed positively.

Finally, column 3 in Table 5 compares unintended migrants with stayers. Interestingly, unintended movers were relatively young and their social networks included more people living abroad. Although such social networks did not seem to affect the decisions of movers (column 1), they seemed to be an important trigger for those who initially had no intentions but in the end did migrate (column 3). 
To analyse whether the regression results presented in Table 5 were robust to an alternative approach of modelling the connection between intentions and behaviour, we could use the two-step Heckman analysis (Heckman 1979). In the first step, the selection of those with emigration intentions was explained using the same model as that in Table 3. In the second step (Table 6), we analysed the factors that explained actual migration behaviour among those who expressed intentions to emigrate $(\mathrm{N}=185)$. Given that the errors in the two equations may be correlated, standard probit models might yield biased results. Thus, the Heckman procedure corrects for possible sample selection bias.

HERE TABLE 6 Two-step Heckman probit analysis of emigration intentions and behaviour, weighted results $(\mathrm{N}=1,489)$

The model of interest in the second step included only a small number of explanatory variables because the number of observations was small. Consequently, we focused on those variables that were of central importance to our discussions about selective immigration policies, in which host countries generally want young, healthy, and highly educated persons, as well as the level of self-efficacy. Self-efficacy is of crucial importance in relation to whether individuals follow through with their plans, and thus we would expect to see a positive effect of self-efficacy on emigration behaviour.

The analysis presented shows that moving from intentions to behaviour is largely unexplained. Only the health status of the respondent provides a clue as to why people depart from their original intentions. Although we found that people in good health were more likely to carry through with their emigration plans than those in poor health, the 
level of self-efficacy was apparently of no importance in relation to effecting plans. A possible reason for this finding is that this element of the theory of planned behaviour was measured in a general non-contextual manner; framing self-efficacy questions in a setting that is specific to migration might yield a greater predictive power.

\section{Conclusions}

Why do people emigrate from a high-income country? In the present paper, we examined the emigration intentions of native-born Dutch residents during 2005 and then assessed whether they actually emigrated during the subsequent five years. We uncovered forces that are supposed to be of considerable importance but hard to measure (Sjaastad 1962) or that were supposed to be covered in time series or longitudinal setups through unobserved heterogeneity in skills, costs, or income components (Gobillon and Le Blanc 2003; Kennan and Walker 2009). However, what can be classified as 'unobserved heterogeneity' remains somewhat of a puzzle. Consequently, in the present paper, we took a different approach to traditional studies of this topic and investigated the effects of both commonly observed characteristics (such as age, work status, and education) and more intangible characteristics (such as personality traits, social networks, and satisfaction with the living conditions in the country of origin).

Three novel results in the paper might improve our future understanding of decision-making in relation to international migration. The first was that the personality of potential migrants and their discontent about the quality of the public domain were strong driving forces in relation to emigration, even given the losses of income that are expected by a substantial number of emigrants (Van Dalen and Henkens 2007; European 
Commission 2010). It is not so much the private gains but the public gains that are linked to moving abroad that weigh heavily in the decision-making process. The overwhelming consensus in the economics of migration is that the private domain is of prime importance to understanding international migration, but - as this study has shown dissatisfaction with the public domain is crucial to grasping emigration from a highincome country such as the Netherlands.

Second, we confirmed that behavioural intentions were good predictors of future emigration: 34 per cent of those who had stated an intention to emigrate actually emigrated within the five-year follow-up period. With regard to such a long-term and potentially permanent decision as emigration, 34 per cent can be seen as relatively high.

Third, the broader group of potential emigrants, namely those who had emigrated and those had not (yet) emigrated, differed little from each other, except in relation to health status. In general, movers were in better health than dreamers. However, the existence of only slight differences between movers and dreamers, raises the question of the degree to which emigration intentions are stable over time. If intentions are stable and if we were to extend the period of observation (say to 12 years), then we could expect a further increase in the realisation rate of intended emigrations.

The study has some noteworthy strengths. Our ability to connect emigration intentions and behaviour with a relatively rich set of predictor variables adds to our current understanding of decision-making processes in relation to emigration and further explains how they are influenced by the characteristics of the private and public domains of life. 
Some limitations should also be mentioned. First, we relied primarily on push factors when explaining emigration. Inclusion of the characteristics and policies of destination countries might provide a more comprehensive picture of the push and pull factors that influence migration from a high-income country.

Second, although we found that having a partner slightly reduced the intention to emigrate, recent research on temporary Dutch labour migration (Van Dalen and Henkens 2012) has suggested that a partner who supports the decision to emigrate can also act as an important stimulus. Future research should also investigate the role of social networks in destination countries, acknowledging that social networks are an important factor not only in the decision of whether to emigrate, but also in terms of the choice of destination country.

A final point concerns the comparability of our findings with the profiles compiled by official statistics agencies. The presented questionnaire focused on adult decision-makers and on people who intended to leave their country of residence on a permanent basis. In contrast, statistical offices rely on the frequently idiosyncratic methods and principles of migration registration (Lemaitre 2005). For instance, a large proportion of Dutch nationals are officially termed emigrants even though they live just across the border in Belgium or Germany and they are fully integrated economically and socially in the Netherlands.

Despite these limitations, the present paper captured more dimensions of migration than are assessed commonly in migration studies. The results presented suggest that Malthus's characterisation of the causes of emigration ('unhappiness of some kind') 
was correct, but today's unhappiness in high-income countries seems to be related much more to dissatisfaction with the public, rather than the private, domain of life.

\section{Appendix}

Composition of samples

To underscore the importance of the oversampling strategy used in the paper we include Table A1, which shows the socio-economic characteristics of those respondents who emigrated in 2005-10 and those in the targeted sample with emigration intentions in 2005 as compared with those in the nationally representative sample.

\section{HERE TABLE A1}

Factor analysis

Table A2 presents the factor analysis on which the scale variables with respect to the public and private domains of the Netherlands were based.

\section{HERE TABLE A2}

\section{References}

Ajzen, I., and M. Fishbein. 1980. Understanding Attitudes and Predicting Social Behaviour. New York: Prentice-Hall.

Ajzen, I. 1991. The theory of planned behaviour, Organizational Behaviour and Human Decision Processes 50 (2): 179-211. 
Becker, G.S. 1975. Human Capital: A Theoretical and Empirical Analysis, with Special Reference to Education. Cambridge MA: NBER.

Berry, J.W. 2001. A psychology of immigration, Journal of Social Issues 57(3): 615-631.

Borghans, L., A.L. Duckworth, J.J. Heckman, and B. ter Weel. 2008. The economics and psychology of personality traits, Journal of Human Resources. 43(4): 972-1059.

Borjas, G.J. 1987. Self-selection and the earnings of immigrants. American Economic Review 77(4): 531-553.

Borjas, G.J. 1991. Immigration and self-selection, in J. Abowd and R. Freeman (eds.), Immigration, Trade and the Labour Market. Chicago: University of Chicago Press, pp. 29-76.

Borjas, G.J., and B. Bratsberg. 1996. Who leaves? The outmigration of the foreign-born, Review of Economics and Statistics 78(1): 165-176.

Bosscher, R.J., and J.H. Smit. 1998. Confirmatory factor analysis of the general selfefficacy scale, Behaviour Research and Therapy 36(3): 339-343.

Boyd, M. 1989. Family and personal networks in international migration: recent developments and new agendas, International Migration Review. 23(3): 638-670

Chiswick, B.R. 1999. Are immigrants favorably self-selected?, American Economic Review, Papers and Proceedings 89(2): 181-185.

Constant, A., and D.S. Massey. 2002. Return migration by German guestworkers: neoclassical versus new economic theories, International Migration 40(4): 5-32.

De Jong, G.F. 2000. Expectations, gender, and norms in migration decision-making, Population Studies 54(3): 307-319. 
De Jong, G.F., and J.T. Fawcett. 1981. Motivations for migration: an assessment and a value expectancy research model,' in G.F. de Jong and R.W. Gardner (eds.), Migration Decision Making. New York: Pergamon Press, pp. 90-129.

DeVoretz, D.J., and C. Iturralde. 2001. Why do high skilled Canadians stay in Canada?, Policy Options (March issue): 59-63.

Drinkwater, S., and P. Ingram. 2009. How different are the British in their willingness to move? Evidence from international social survey data, Regional Studies. 43(2): 287-303.

Duncan, G.J., and S.J. Newman. 1976. Expected and actual residential mobility, Journal of the American Institute of Planners. 42(2): 174-186.

Epstein, G.S., and I. Gang. 2006. The influence of others on migration plans, Review of Development Economics. 10(4): 652-665.

European Commission. 2010. Geographical and Labour Market Mobility, report on Special Eurobarometer no. 337, Luxembourg: EC.

Fishbein, M., and I. Ajzen. 1975. Belief, Attitude, Intention and Behaviour. Reading MA: Addison-Wesley.

Frieze, I.H., and M.Y. Li. 2010. Mobility and personality, in S.C. Carr (ed.), The Psychology of Global Mobility. New York: Springer Verlag, pp. 87-104.

Gardner, R.W., G.F. De Jong, F. Arnold, and B.V. Carino. 1986. The best-laid schemes: an analysis of discrepancies between migration intentions and behaviour, Population and Environment 8(1-2): 63-77.

Geis, W., S. Uebelmesser, and M. Werding. 2011. Why go to France or Germany, if you could as well go to the UK or the US? Selective features of immigration to the EU 
'Big Three' and the United States, Journal of Common Market Studies. 49(4): 767-796.

Gobillon, L., and D. Le Blanc. 2003. Migrations, incomes and unobserved heterogeneity, Working paper. London: University College of London.

Hatton, T.J., and J.G. Williamson. 1998. The Age of Mass Migration - Causes and Economic Impact. Oxford: Oxford University Press.

Hatton, T.J., and J.G. Williamson.2011. Are third world emigration forces abating?, World Development 39(1): 20-32.

Heckman, J. 1979. Sample selection bias as a specification error, Econometrica 47(1): $153-161$.

Horvath, P., and M. Zuckerman. 1993. Sensation seeking, risk appraisal, and risky behaviour, Personality and Individual Differences 14(1): 41-52.

Hughes, G.A., and B. McCormick. 1985. Migration intentions in the UK - which households want to migrate and which succeed?, Economic Journal 95(Supplement): 113-123.

Hugo, G., D. Rudd, and K. Harris. 2001. Emigration from Australia - Economic Implications, CEDA Information Report no. 77. Melbourne: Committee for Economic Development of Australia.

Kalmijn, M., P. de Graaf, and A. Poortman. 2004. Interactions between cultural and economic determinants of divorce in the Netherlands. Journal of Marriage and Family 66(1): 75-89.

Kan, K. 1999. Expected and unexpected residential mobility. Journal of Urban Economics 45(1): 72-96. 
Kaul, I., and R.U. Mendoza. 2004. Advancing the concept of public goods, in I. Kaul, P. Conceicao, K. Le Goulven, and R.U. Mendoza (eds.), Providing Global Public Goods - Managing Globalization. Oxford: Oxford University Press, pp. 78-111

Kennan, J., and J.R. Walker. 2009. The effect of expected income on individual migration decisions, Working paper. Madison: University of Wisconsin.

Knapp, T.A., and P.E. Graves. 1989. On the role of amenities in models of migration and regional development, Journal of Regional Science 29(1): 71-87.

Krieger, H. 2005. Migration Trends in An Enlarged Europe, Dublin: European Foundation for the Improvement of Living and Working Conditions.

Lemaitre, G. 2005. The comparability of international migration statistics, Statistics Brief OECDJuly 2005, 9: 2-8.

Liebig, Th., and A. Sousa-Poza. 2004. Migration, self-selection and income inequality: an international perspective, Kyklos 57(1): 125-146.

Lu, M. 1998. Analyzing migration decisionmaking: relationships between residential satisfaction, mobility intentions, and moving behaviour, Environment and Planning A, 30(8): 1473-1495.

Lu, M. 1999. Do people move when they say they will? Inconsistencies in individual migration behaviour, Population and Environment 20(35): 467-488.

Malthus, T.R.. 1798. An Essay on the Principle of Population. Harmondsworth: Penguin. Massey, D.S. 1999. Why does immigration occur?, in C. Hirschman, P. Kasinitz, and J. DeWind (eds.), The Handbook of International Migration: The American Experience. New York: Russell Sage Foundation, pp. 34-52.

Mincer, J. 1978. Family migration decisions, Journal of Political Economy 86(5): 749773. 
Nunnally, J.C. 1978. Psychometric Theory. New York: McGraw Hill.

OECD. 2011. Society at a Glance 2011 - OECD Social Indicators. Paris: OECD.

Petersen, W. 1952. Some Factors Influencing Postwar Emigration from the Netherlands. The Hague: Martinus Nijhoff.

Poutvaara, P., M.D. Munk, and M. Junge. 2009. Self-selection and earnings of emigrants from a welfare state. IZA Discussion Paper no. 4144. Bonn: IZA.

Salt, J., and P. H. Rees. 2006. Globalisation, Population Mobility and Impact of Migration on Population, ESRC Seminar Series. Swindon: Economic and Social Research Council.

Sherer, M., J.E. Maddux, B. Mercandante, S. Prentice-Dunn, B. Jacobs, and R.W. Rogers. 1982. The self-efficacy scale: construction and validation, Psychological Reports 51: 663-671.

Sjaastad, L.A. 1962. The costs and returns of human migration, Journal of Political Economy 70(5): 80-93.

Stark, O., and D.E. Bloom. 1985. The new economics of labour migration, American Economic Review 75(2): 191-196.

Sutton, S. 1998. Predicting and explaining intentions and behaviour: how well are we doing?, Journal of Applied Social Psychology 28(15) 1317-1338.

Sutton S, 2003. Testing attitude-behaviour theories using non-experimental data: an examination of some hidden assumptions, European Review of Social Psychology 13(1): 293-323.

Thoits P. 2011. Mechanisms linking social ties and support to physical and mental health, Journal of Health and Social Behavior 52(2): 154-162. 
Uebelmesser, S. 2006. To go or not to go: emigration from Germany, German Economic Review 7(2): 211-231.

Van Dalen, H.P., G. Groenewold, and J.J. Schoorl. 2005. Out of Africa: what drives the pressure to emigrate?, Journal of Population Economics 18(4): 741-778.

Van Dalen, H.P., and K. Henkens. 2007. Longing for the good life: understanding emigration from a high-income country, Population and Development Review 33(1): $17-45$.

Van Dalen, H.P., and K. Henkens. 2012. Explaining low international labour mobility: the role of networks, personality and perceived labour market opportunities, Population, Space and Place 18(1): 31-44.

Vandenbrande, T., L. Coppin, P. van der Hallen, P. Ester, D. Fourage, A. Fasang, S. Geerdes, and K. Schömann. 2006. Mobility in Europe. Dublin: European Foundation for Improvement of Living and Working Conditions.

Watters, J.K., and P. Biernacki. 1989. Targeted sampling: options for the study of hidden populations, Social Problems 36(4): 416-430.

Winship, C., and L. Radbill. 1994. Sampling weights and regression analysis, Sociological Methods \& Research 23(2): 230-257.

Zuckerman, M. 1971. Dimensions of sensation seeking, Journal of Consulting and Clinical Psychology 36(1): 45-52. 
Table 1: Descriptive statistics of emigrants versus stayers, the Netherlands (2005-10)

\begin{tabular}{|c|c|c|c|c|}
\hline \multirow[b]{3}{*}{ Sex $($ male $=0$, female $=1)$} & \multicolumn{2}{|c|}{ Emigrants } & \multicolumn{2}{|c|}{ Stayers } \\
\hline & Mean & $\begin{array}{l}\text { Standard } \\
\text { deviation }\end{array}$ & Mean & $\begin{array}{l}\text { Standard } \\
\text { deviation }\end{array}$ \\
\hline & $39 \%$ & 0.49 & $46 \%$ & 0.50 \\
\hline Age (in years) & 38.3 & 9.56 & 49.4 & 14.9 \\
\hline Partner (no partner $=0$ ) & $82 \%$ & 0.39 & $72 \%$ & 0.45 \\
\hline Number of children in household & 1.06 & 1.26 & 1.51 & 1.34 \\
\hline \multicolumn{5}{|l|}{ Employment status } \\
\hline Employed & $70 \%$ & 0.46 & $53 \%$ & 0.50 \\
\hline Not working & $19 \%$ & 0.40 & $43 \%$ & 0.50 \\
\hline Self-employed & $10 \%$ & 0.31 & $4 \%$ & 0.20 \\
\hline \multicolumn{5}{|l|}{ Income (net per month) } \\
\hline Less than 2500 euros & $43 \%$ & 0.50 & $58 \%$ & 0.49 \\
\hline $2500-4000$ euros & $36 \%$ & 0.48 & $32 \%$ & 0.47 \\
\hline More than 4000 euros & $18 \%$ & 0.39 & $07 \%$ & 0.26 \\
\hline Health status & 4.39 & 0.63 & 3.98 & 0.77 \\
\hline \multicolumn{5}{|l|}{ Educational level } \\
\hline Low & $18 \%$ & 0.39 & $28 \%$ & 0.45 \\
\hline Intermediate & $30 \%$ & 0.46 & $33 \%$ & 0.47 \\
\hline High & $52 \%$ & 0.50 & $39 \%$ & 0.49 \\
\hline Number of network contacts & 2.91 & 4.27 & 2.02 & 3.46 \\
\hline \multicolumn{5}{|l|}{ Personality traits: } \\
\hline Self-efficacy & 3.99 & 0.54 & 3.74 & 0.58 \\
\hline Sensation-seeking & 3.50 & 0.77 & 3.09 & 0.73 \\
\hline \multicolumn{5}{|l|}{ Evaluations of: } \\
\hline Private living conditions & 2.40 & 0.59 & 2.25 & 0.61 \\
\hline Welfare state institutions & 2.85 & 0.71 & 2.57 & 0.70 \\
\hline Environmental quality & 3.78 & 0.89 & 3.32 & 0.72 \\
\hline Societal problems & 3.67 & 0.65 & 3.41 & 0.59 \\
\hline $\mathrm{N}=$ & \multicolumn{2}{|c|}{77} & \multicolumn{2}{|c|}{1,412} \\
\hline
\end{tabular}

Source: NIDI emigration survey (2005-10) 
Table 2: Emigration intentions and subsequent behaviour, the Netherlands (200510)

\begin{tabular}{|c|c|c|c|}
\hline $\begin{array}{l}\text { Emigration } \\
\text { intentions in } 2005^{1}\end{array}$ & $\begin{array}{l}\text { Distribution of } \mathrm{N} \\
\text { in } 2005 \\
\text { (1) }\end{array}$ & $\begin{array}{c}\text { Numbers emigrated } \\
\text { in } 2010 \\
\text { (2) }\end{array}$ & $\begin{array}{l}\text { Percentage emigrated in } \\
2010 \\
\text { (2) as percentage of (1) }\end{array}$ \\
\hline Certainly not & 703 & 3 & $0.4 \%$ \\
\hline Probably not & 393 & 2 & $0.5 \%$ \\
\hline Maybe & 208 & 10 & $4.8 \%$ \\
\hline Yes, probably & 79 & 13 & $16.5 \%$ \\
\hline Yes, certainly & 106 & 49 & $46.2 \%$ \\
\hline Total N & 1,489 & 77 & $5.2 \%$ \\
\hline
\end{tabular}

Notes:

(1) The emigration intention question was stated as: 'Do you intend to emigrate in the near future?'

Source: As for Table 1. 
Table 3: Analysis of emigration intentions and behaviour in the Netherlands, 200510

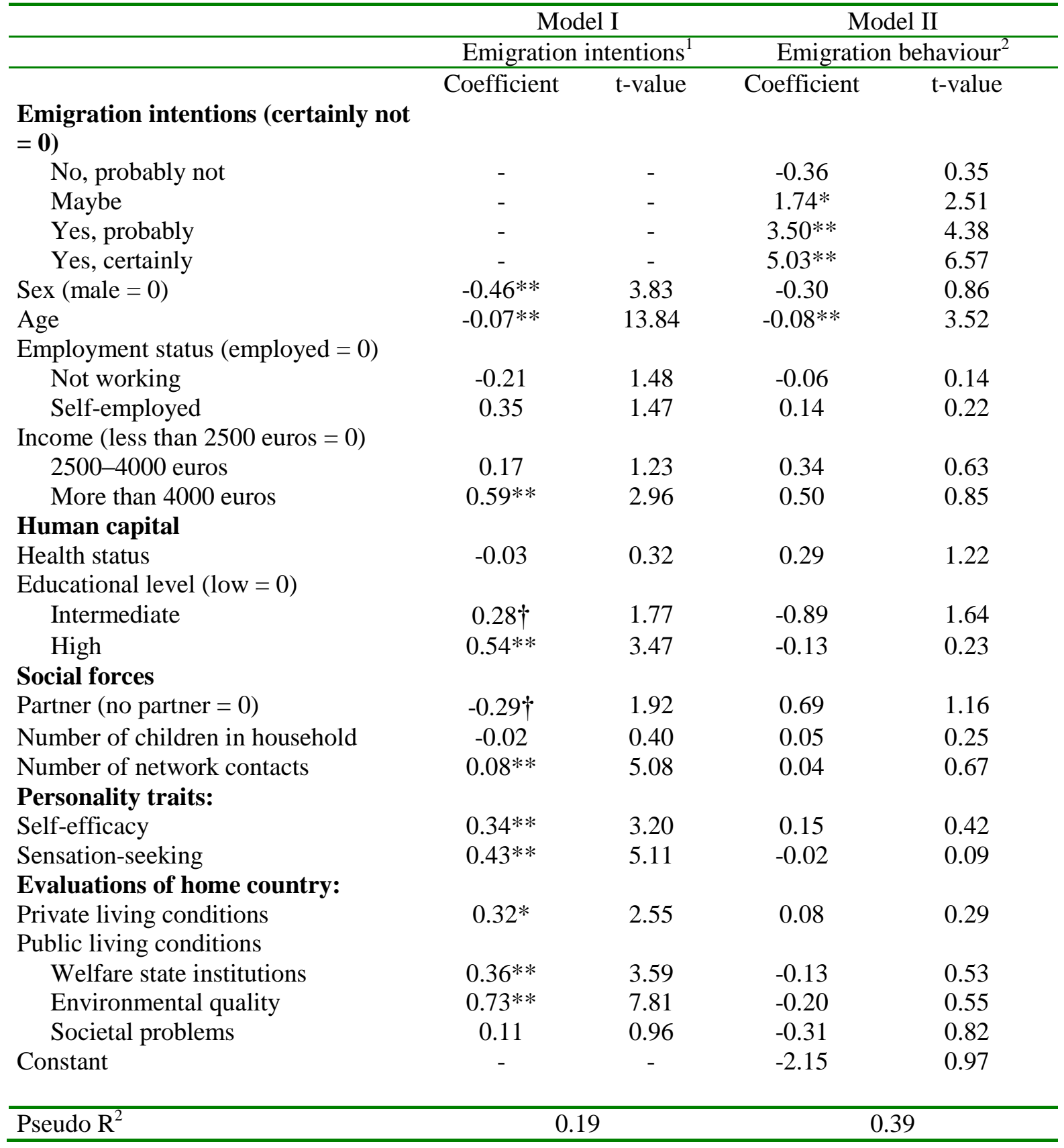

Notes:(1) Estimated with ordered logit, estimated cut-off points are not reported.

(2) Estimated by means of logit analysis $(0=$ stayed in the Netherlands; $1=$ emigrated $)$.

$\dagger \mathrm{p}<0.10 ; * \mathrm{p}<0.05 ; * * \mathrm{p}<0.01 ; \mathrm{N}=1,489$

Source: As for Table 1 . 
Table 4: Groups for the analysis of intentions and behaviour, the Netherlands (200510)

\begin{tabular}{|lc|c|c|}
\cline { 3 - 4 } \multicolumn{1}{c|}{} & \multicolumn{2}{c|}{ Emigration intentions } \\
\hline Emigrated & Yes & Yes & No \\
& & $\mathrm{N}=62$ & $\mathrm{II}$ (Unintended movers) \\
& No & III (Dreamers) & IV (Stayers) \\
\cline { 2 - 3 } & & $\mathrm{N}=123$ & $\mathrm{~N}=1,289$ \\
\hline
\end{tabular}

Source: As for Table 1. 
Table 5: Multinomial logit analysis explaining emigration behaviour in the

\section{Netherlands (stayers $=$ reference category), weighted results $(N=1,489)$}

\begin{tabular}{|c|c|c|c|c|c|c|}
\hline \multirow[b]{3}{*}{$\begin{array}{l}\text { Individual background } \\
\text { characteristics }\end{array}$} & \multicolumn{2}{|c|}{ Movers $^{\mathrm{a}}$} & \multicolumn{2}{|c|}{ Dreamers $^{\mathrm{a}}$} & \multicolumn{2}{|c|}{ 'Unintended' movers ${ }^{\mathrm{a}}$} \\
\hline & \multicolumn{2}{|c|}{$(1)$} & \multicolumn{2}{|c|}{ (2) } & \multicolumn{2}{|c|}{$(3)$} \\
\hline & Coefficient & $t$ value & Coefficient & $t$ value & Coefficient & $t$ value \\
\hline Sex $($ male $=0$, female $=1)$ & $-0.54 \dagger$ & 1.68 & -0.22 & 0.96 & -0.35 & 0.72 \\
\hline Age & $-0.05 * *$ & 4.01 & $-0.05 * *$ & 4.45 & $-0.14 * *$ & 3.71 \\
\hline \multicolumn{7}{|l|}{ Employment status $($ Employed $=0)$} \\
\hline Not working & -0.16 & 0.36 & -0.33 & 1.05 & -0.35 & 0.59 \\
\hline Self-employed & 0.69 & 1.24 & $0.83^{*}$ & 1.99 & -0.20 & 0.21 \\
\hline \multicolumn{7}{|l|}{ Income (less than 2500 euros $=0$ ) } \\
\hline 2500-4000 euros & 0.49 & 1.20 & -0.29 & 0.99 & -0.11 & 0.14 \\
\hline Less than 4000 euros & 0.69 & 1.31 & -0.29 & 0.65 & -0.03 & 0.04 \\
\hline \multicolumn{7}{|l|}{ Human capital } \\
\hline Health status & $0.79 * *$ & 2.89 & 0.24 & 1.23 & 0.11 & 0.27 \\
\hline \multicolumn{7}{|l|}{ Educational level $($ low $=0)$} \\
\hline Intermediate & -0.28 & 0.61 & 0.33 & 0.99 & -1.23 & 1.41 \\
\hline High & -0.21 & 0.44 & 0.06 & 0.16 & 0.07 & 0.09 \\
\hline \multicolumn{7}{|l|}{ Social forces } \\
\hline Number of network contacts & 0.04 & 1.18 & $0.07 * *$ & 2.64 & $0.15^{*}$ & 2.07 \\
\hline Partner $($ no partner $=0$ ) & -0.15 & 0.33 & 0.23 & 0.67 & 1.90 & 1.46 \\
\hline Number of children in household & -0.05 & 0.30 & -0.01 & -0.01 & 0.05 & 0.14 \\
\hline \multicolumn{7}{|l|}{ Personality traits } \\
\hline Self-efficacy & $0.73 * *$ & 2.57 & $0.91 * *$ & 3.77 & 0.47 & 0.92 \\
\hline Sensation-seeking & $0.40 \dagger$ & 1.92 & $0.45 * *$ & 2.86 & 0.29 & 0.90 \\
\hline \multicolumn{7}{|l|}{ Evaluation of home country ${ }^{b}$} \\
\hline Private living conditions & $0.49 \dagger$ & 1.93 & $0.49 *$ & 2.19 & 0.32 & 0.69 \\
\hline Welfare state institutions & 0.25 & 1.29 & $0.48 * *$ & 2.72 & 0.05 & 0.13 \\
\hline Societal problems & $0.78 * *$ & 3.08 & 0.27 & 1.24 & $-0.88 \dagger$ & 1.79 \\
\hline Environmental quality & $0.81 * *$ & 3.25 & $0.78^{* *}$ & 3.96 & -0.08 & 0.13 \\
\hline Constant & $-17.07 * *$ & 7.41 & $-14.16 * *$ & 8.94 & -1.52 & 0.48 \\
\hline Pseudo $\mathrm{R}^{2}$ & \multicolumn{6}{|c|}{0.24} \\
\hline Log pseudo-likelihood & \multicolumn{6}{|c|}{-235.4} \\
\hline Wald $\left[\chi^{2}(54)\right]$ & \multicolumn{6}{|c|}{438.1} \\
\hline
\end{tabular}

(1) Emigrants $=$ those with intentions who have emigrated; Dreamers $=$ those with intentions who have not (yet) emigrated; Stayers $=$ those with no intentions who have not emigrated; Unintended movers $=$ those with no intentions in 2005 who actually moved between 2005 and January 2011. 
(2) To interpret these results: the higher the score, the more negative an individual is about the quality of the domain in question.

$$
\dagger \mathrm{p}<0.10 ; * \mathrm{p}<0.05 ; * * \mathrm{p}<0.01 \text {. }
$$

\section{Source: As for Table 1.}


Table 6: Two-step Heckman probit analysis of emigration intentions and behaviour, weighted results $(\mathrm{N}=1,489)^{1}$

\begin{tabular}{lcc}
\hline & Emigration $(\mathrm{no}=0$, yes $=1)$ \\
\hline Emigration behaviour explained by: & Coefficient & $t$ value \\
Age & -0.00 & 0.01 \\
Health status & $0.28^{*}$ & 2.18 \\
Educational level (Low $=0)$ & -0.21 & 0.74 \\
$\quad$ Intermediate & 0.06 & 0.21 \\
$\quad$ High & -0.05 & 0.29 \\
Self-efficacy & 1.40 & 1.15 \\
Constant & & \\
& & 0.86 \\
Wald $\chi^{2}(5)$ & \multicolumn{2}{c}{$-0.02(0.11)$} \\
Prob $>\chi^{2}$ & \multicolumn{2}{c}{0.91} \\
$\rho$ (t-value) & 185 \\
Wald test independence equations & \multicolumn{2}{c}{} \\
Uncensored observations & \multicolumn{2}{c}{} \\
\hline
\end{tabular}

Notes:

(1) The selection equation (first step) explains a binary variable 'emigration intentions' (categories 'certainly not' and 'probably not' and 'maybe' = 0; 'probably' and 'certainly'

=1) by means of all the explanatory variables of model I in Table 3.

$* \mathrm{p}<0.05$.

Source: As for Table 1. 
Table A1: Demographic characteristics of potential and actual emigrants in the targeted and nationally representative samples

\begin{tabular}{|c|c|c|c|c|c|c|c|c|}
\hline & \multicolumn{4}{|c|}{ Respondents with emigration intentions } & \multicolumn{4}{|c|}{ Emigrated respondents in samples: } \\
\hline & \multicolumn{2}{|c|}{ Targeted } & \multicolumn{2}{|c|}{ National } & \multicolumn{2}{|c|}{ Targeted } & \multicolumn{2}{|c|}{ National } \\
\hline & Mean & $\begin{array}{l}\text { Standard } \\
\text { deviation }\end{array}$ & Mean & $\begin{array}{l}\text { Standard } \\
\text { deviation }\end{array}$ & Mean & $\begin{array}{l}\text { Standard } \\
\text { deviation }\end{array}$ & Mean & $\begin{array}{l}\text { Standard } \\
\text { deviation }\end{array}$ \\
\hline Sex $($ male $=0)$ & $39 \%$ & 0.49 & $53 \%$ & 0.51 & $39 \% *$ & 0.47 & $75 \% *$ & 0.45 \\
\hline Age (in years) & 39.7 & 9.18 & 42.3 & 12.06 & $39.4 *$ & 9.08 & $32.7^{*}$ & 10.53 \\
\hline Partner & $80 \%$ & 0.39 & $74 \%$ & 0.45 & $86 \%$ & 0.35 & $75 \%$ & 0.45 \\
\hline Number of children & 1.03 & 1.23 & 1.36 & 1.25 & 1.03 & 1.25 & 1.25 & 1.36 \\
\hline \multicolumn{9}{|l|}{ Income level } \\
\hline Less than 2500 euros & $48 \%$ & 0.50 & $58 \%$ & 0.50 & $42 \%$ & 0.50 & $50 \%$ & 0.52 \\
\hline 2500-4000 euros & $32 \%$ & 0.47 & $26 \%$ & 0.45 & $37 \%$ & 0.49 & $33 \%$ & 0.49 \\
\hline More than 4000 euros & $14 \%$ & 0.34 & $8 \%$ & 0.27 & $18 \%$ & 0.39 & $17 \%$ & 0.39 \\
\hline \multicolumn{9}{|l|}{ Educational level } \\
\hline Low & $18 \%$ & 0.39 & $11 \%$ & 0.31 & $17 \%$ & 0.38 & $25 \%$ & 0.45 \\
\hline Intermediate & $35 \%^{1}$ & 0.48 & $53 \%^{1}$ & 0.51 & $32 \%$ & 0.47 & $17 \%$ & 0.39 \\
\hline High & $46 \%$ & 0.50 & $37 \%$ & 0.49 & $51 \%$ & 0.50 & $58 \%$ & 0.51 \\
\hline $\mathrm{N}=$ & \multicolumn{2}{|r|}{147} & \multicolumn{2}{|r|}{38} & \multicolumn{2}{|c|}{65} & \multicolumn{2}{|c|}{12} \\
\hline
\end{tabular}

Notes:

(1) The difference is not significant in a $\chi^{2}$-test, but is different when using a two-sided t-test at $\mathrm{p}<0.05$.

$* \mathrm{p}<0.05$

Source: As for Table 1. 
Table A2: Results of a principal component analysis with Varimax rotation on 16

items for living conditions in the Netherlands $(N=1,489)$

\begin{tabular}{lcccc}
\hline $\begin{array}{l}\text { Evaluation of characteristics of } \\
\text { home country }\end{array}$ & Factor 1 & Factor 2 & Factor 3 & Factor 4 \\
\hline Welfare state institutions & & & & \\
Health care system & $\mathbf{0 . 8 0}$ & 0.05 & 0.06 & 0.10 \\
Social security & $\mathbf{0 . 8 4}$ & 0.10 & 0.05 & 0.17 \\
Educational services & $\mathbf{0 . 7 5}$ & 0.04 & 0.23 & 0.07 \\
System of law and order & $\mathbf{0 . 6 7}$ & 0.33 & 0.02 & 0.09 \\
Pension system & $\mathbf{0 . 7 7}$ & 0.14 & -0.01 & 0.13 \\
Societal problems & & & & \\
Crime level & 0.19 & $\mathbf{0 . 7 8}$ & 0.04 & 0.05 \\
Pollution level & 0.09 & $\mathbf{0 . 5 5}$ & 0.30 & 0.07 \\
Mentality & 0.26 & $\mathbf{0 . 5 6}$ & 0.18 & 0.07 \\
Ethnic diversity & 0.12 & $\mathbf{0 . 6 7}$ & 0.13 & 0.08 \\
Environmental quality & & & & \\
Nature and space & 0.15 & 0.00 & $\mathbf{0 . 8 2}$ & 0.11 \\
Population density & 0.05 & 0.44 & $\mathbf{0 . 6 5}$ & 0.07 \\
Noise pollution & 0.02 & 0.09 & $\mathbf{0 . 8 3}$ & 0.03 \\
Private living conditions & & & & \\
Home & 0.11 & -0.10 & 0.27 & $\mathbf{0 . 6 4}$ \\
Income & 0.25 & 0.08 & 0.01 & $\mathbf{0 . 7 2}$ \\
Working conditions & 0.13 & 0.23 & 0.00 & $\mathbf{0 . 7 3}$ \\
Social contacts & 0.11 & -0.02 & 0.12 & $\mathbf{0 . 6 9}$ \\
Eigenvalue & & & & \\
R & 4.61 & 1.95 & 1.60 & 1.20 \\
\hline
\end{tabular}

Source: As for Table 1. 
Figure 1: Dissatisfaction with living conditions in the Netherlands, by migration status

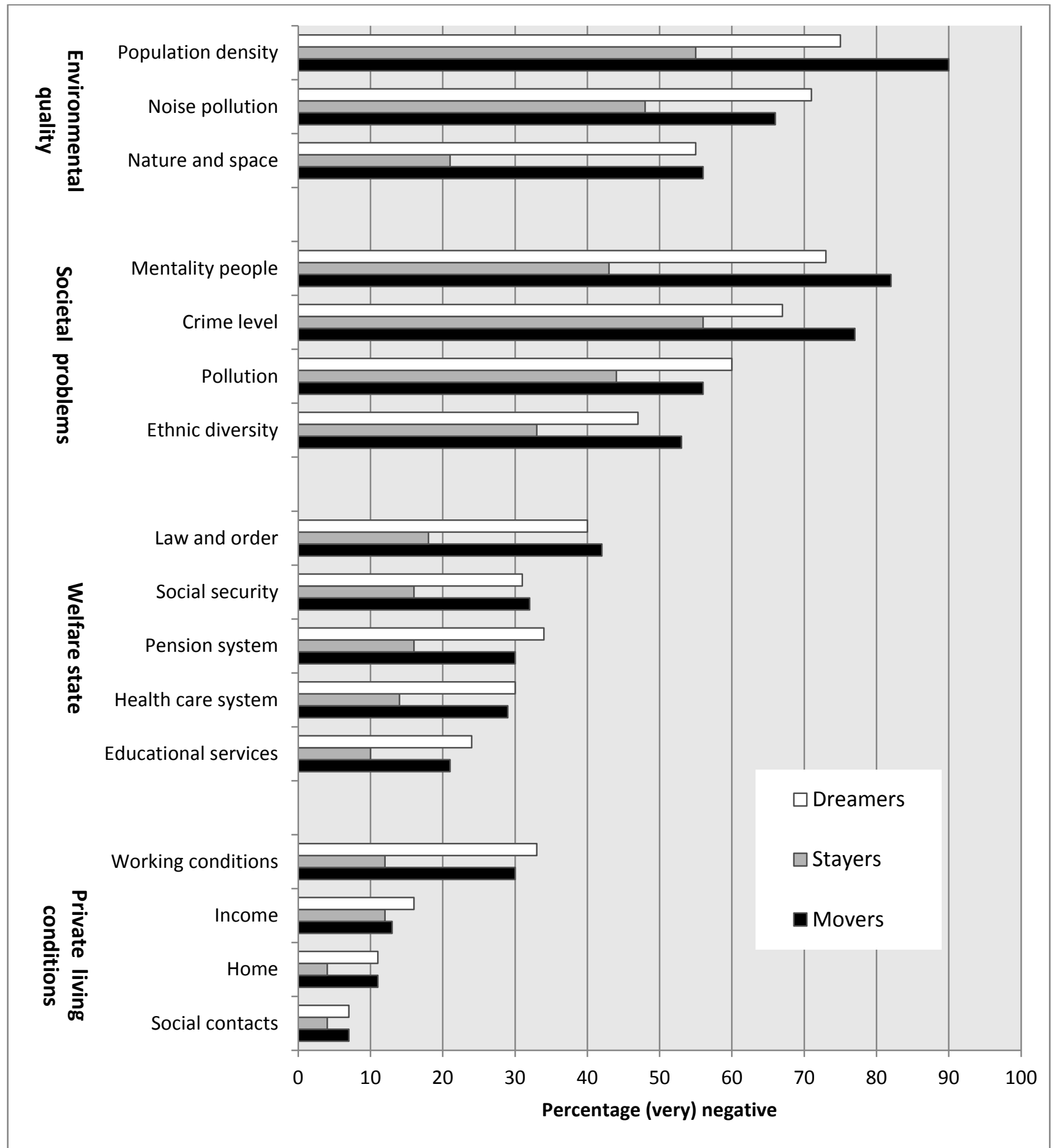

Source: As for Table 1. 